\title{
PULSED LASER DEPOSITION OF HIGH Tc SUPERCONDUCTING THIN FILMS:
}

PRESENT AND FUTURE

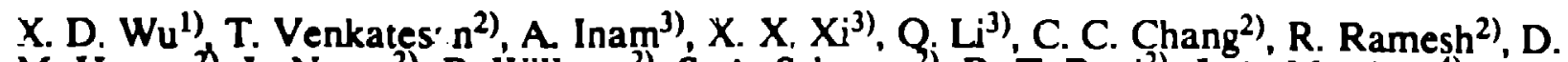
M. Hwang ${ }^{2)}$, L Nazar), B. Wilkens') S. A. Schwarz ${ }^{2}$, R. T. Ravi'), J. A. Martinez') J. B.

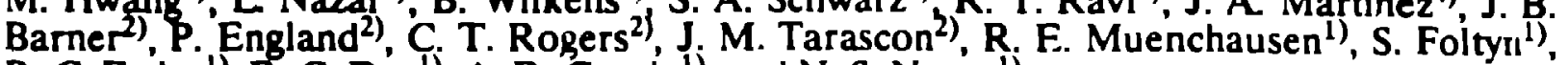
R. C. Estler ${ }^{(1)}$, R. C. Dye', A. R. Garcia ${ }^{1)}$, and N. S. Nogari)

1)ERDC, Los Alamos National Laboratory, Los Alamos, NM 87545

2) Bellcore, Red Bank, NJ 07701

3) Physics Department, Rutgers University, Piscataway, NJ 08854

4)Departamento de Fisica, Universidad Nacional de La Plata (UNLP), Argentina

\section{ABSTRACT}

Pulsed laser depositioi. (PLD) has been widely used for deposition of high $T_{c}$ superconducting thin films, and has been approved as one of the best physical vapor techniques 10 prepare the films. The most important advantage of this technique is stoichiometric deposition, namely the films could be made with the same composition of the targets. Utilized PLD, not only thin films but also multilayers and superlattices of high

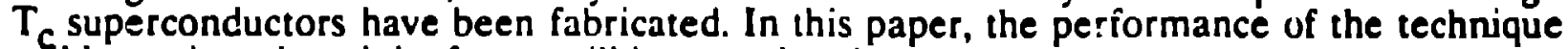
will be reviewed, and the future will be speculated.

\section{INTRODUCTION}

Utilizing laser irradiation as an energy source to vaporize materials and form thin films has been researched over the lasi twenty years. An excellent review has been given by Cheung and Sankur in 1988 [1]. The successful use of laser deposition of high $T_{\text {super- }}$ conducting thin films has brought world-wide attention to this less well known thin film deposition technique. Laser deposition is becoming a strong contender among various vapor deposition techniques for deposition of not only superconducting thin films, insulators, and metals but also for multilayers and superlattices.

\section{CHOICE OF LASERS}

There are various lasers (both pulsed and $\mathrm{cw}$ ) with wavelengths from ultraviolet to far-infrared are commonly available. The choice of the lasers depends on specific applications as discussed by Boyd [2]. In applicutions where melting and evaporation are desired, the pulsed lasers have been selected because of their high power outputs.

The absorption coefficient of the material plays an important role in the lasermaterial interaction process [1-2]. The higher the absorption coefficient, the thinner surface layer will be heated to the vaporization point. Moreover, the reflectivity should be small in order to incorporate the optical energy to the material more efficiently. In table 1 , estimated values of absorption coefficient and reflectivity for $\mathrm{YB}_{2} \mathrm{Cu}_{3} \mathrm{O}_{7-x}$ are given for lew selected wavelengths. Those values are calculated from the cuta of optic transmission or ellipsometry measurement on $\mathrm{YBa}_{2} \mathrm{Cu}_{3} \mathrm{O}_{7-x}$ superconducting thin films [3-5]. The values could be different for bulk materials. The large absorption coefficient and small reflectivity at $193 \mathrm{~nm}, 248 \mathrm{~nm}$ and $308 \mathrm{~nm}$ make excimer lasers the choice for deposition of high $T_{\text {c }}$ superconducting thin films. Though large wavelength lasers such as $1064 \mathrm{~nm}$ Yd:YAG laser were employed for thin film deposition, the superconducting properties of the deposited films were generally worse than those deposited using excimer lasers [5-6].

\section{SUPERCONDUCTORS}

Which high Tc superconductor should be the choice for target material? As we know, there are a number of $\mathrm{Cu}$-based oxides which are superconducting 0 ;er $77 \mathrm{~K}$ [7-9]. 
Table 1. Estimated values of absorption coefficient $(\alpha)$ and reflectivity (R) for $\mathrm{KBa}_{2} \mathrm{Cu}_{3} \mathrm{O}_{7-2}$.

\begin{tabular}{|c|c|c|c|}
\hline Laser & $\begin{array}{c}\text { Wavelength } \\
(\mu \mathrm{m})\end{array}$ & $\begin{array}{c}\alpha \\
\left(10^{3} \mathrm{~cm}^{-1}\right)\end{array}$ & $\boldsymbol{R}$ \\
\hline Carbon Dioxide & $\sim 10$ & 0.5 & 0.75 \\
\hline Nd:YAG & 1.064 & 1.2 & 0.18 \\
\hline Vd:YAG $(\lambda / 2)$ & 0.533 & 1.5 & 0.14 \\
\hline Nd:YAG $(\lambda / 3)$ & 0.355 & 1.7 & 0.12 \\
\hline Excimer & & & \\
XeCl & 0.308 & 1.9 & 0.12 \\
KrF & 0.248 & 2.3 & 0.13 \\
ArF & 0.193 & 2.4 & 0.15 \\
\hline
\end{tabular}

From an application point of view, a higher superconducting transition temperature would be desired. So far, Th-based superconductors have the highest transition temperature of 125 $K$ [9]. The main problem for making Tl-base oxide superconducting thin film is not the toxic issue of the materials but the existence of many superconducting phases winich are formed at similar processing conditions. This creates difficulties to form single phase superconducting thin films with higher transition temperatures. Bi-based superconductors have the same problem. Loss of $\mathrm{T}$ and $\mathrm{Bi}$ at high substrate remperatures also introduces extra problems for thin film fabrication. That is why 50) far there are no good superconducting thin films with transition temperatures over $100 \mathrm{~K}$. Certainly, it is a challenge to solve the mentioned problems.

At this moment, the choice of supe-conduc :-s for thin film fabrication is $90 \mathrm{~K}$ $\mathrm{ReBa} \mathrm{Cu}_{3} \mathrm{O}_{7}$ ( $\mathrm{Re}-\mathrm{Y}, \mathrm{Dy}, \mathrm{Ho}, \mathrm{Er}, \mathrm{Gd}, \ldots$ ) (so called "123" superconjuctors). The "123" superconducting thin films are much easier to be formed in a single phase. Many groups are able to make "123" superconducting thin film with critical current densities of $5 \times 10^{6}$ $\mathrm{A} / \mathrm{cm}^{2}$ at $77 \mathrm{~K}$, which is the highest for any superconductors. For this reason, we will restrict our discussions only for $\mathrm{YBa}_{2} \mathrm{Cu}_{3} \mathrm{O}_{7 \cdot x}(\mathrm{YBaCuO})$.

YBaCuO has an orthorhombic structure with $a=0.382 \mathrm{~nm}, \mathrm{~b}=0.389 \mathrm{~nm}$ and $c=1.168 \mathrm{~nm}$. For the material to be superconducting, one must be able to (1) make films with right composition, (2) get right crystalline phase, and (3) produce the right oxygen stoichiometry in the films.

\section{STOICHOMETRIC DEPOSITION}

Thin film depusition process can be divided into three steps: vaporization of the source material, transporting the vaporized material to substrate, and film nucleation on the substrate surface. The ideal way for thin film fabrication is to use a stoichiometric target, and obtain fiims with the same composition of the target.

Congruent evaporation is the most unique feature of pulsed laser deposition [1]. For a multicomponent material, the pulse heating enables all components to be evaporate instantly. Though pulsed laser deposition had been used for preparation of thin film of BaPbBlo [10], which has $T_{c}$ of $13 \mathrm{~K}$ it was first reported by bijkkamp et. al [11] that a multi-element oxide could be denosited stoichiometricallv hv nulsed excimer laser 
deposition. Fig. 1 shows a Rutherford backscattering (RBS) spectrum of a Y-Ba-Cu oxide film on a carbon substrate (solid line) made from a stoichiometric $\mathrm{YBa}_{2} \mathrm{Cu}_{3} \mathrm{O}_{7.2}$ target at room temperature in vacuum. It is obvious that the film had a composition very close to the target as evident from the simulation (dashed line) assuming $Y: B a: C u: O=1: 2: 3: 6$. The stoichiometric deposition indicates congruent evaporation of the superconductor by pulsed laser heating, and unite or same sticking coefficients for all the elements. The small loss of oxygen in vacuum is obvious. The large amount of oxygen found in the film deposited in vacuum shows strong evidence for existence of oxides or sub-oxides in the evaporated material, which was confirmed by a mass spectroscopic study [12].

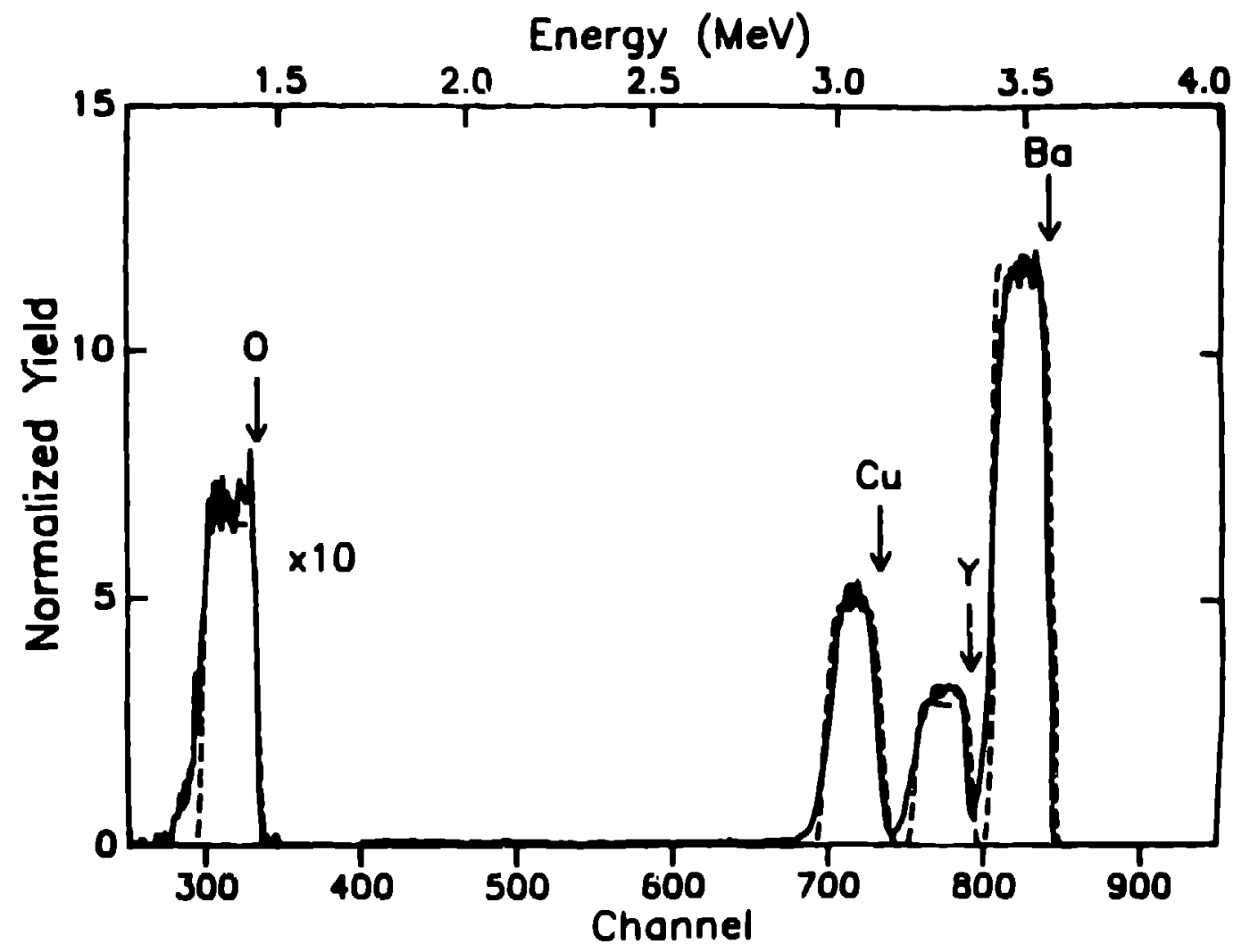

Fig. 1 RBS Spectrum ( $4 \mathrm{MeV} \mathrm{He}{ }^{++}$) of an as-deposited $\mathrm{Y}-\mathrm{Ba}-\mathrm{Cu}$ oxide thin film on a carbon substrate (solid line) made at room temperatuie in vacuum, overlayed with a simulation (dashed line) of $190 \mathrm{~nm} \mathrm{YBa}_{2} \mathrm{Cu}_{3} \mathrm{O}_{6}$.

The pulsed laser deposition process is rather complicated as shown by a further study. In the experiment [13], a pulsed laser $(248 \mathrm{~nm}, 30 \mathrm{~ns})$ was incident on a rotating target at an angle of 45 degrees. The substrate was held in parallel with the $\mathrm{YBa}_{2} \mathrm{Cu}_{3} \mathrm{O}_{7-x}$ target. The angular distributions of composition and thickness of the deposited fifms werf measured by RBS [13]. The data in Fig. 2 was obtained at an energy density of $1.5 \mathrm{~J} / \mathrm{cm}^{2}$, and the angle was defined as trom the normal direction of the target. The results clearly showed that the deposition was forward-directed, and the composition for large angles was deviated from the ideal one such as in the center of the deposition. It was also found that there is a laser energy density threshold $\left(-1 \mathrm{~J} / \mathrm{cm}^{2}\right.$ for the excimer luser) to obtain correct composition even at the center (13). Since more particles (size up $101000 \mathrm{~nm}$ in diameter, on the film surfaces) per unit thickness were found at higher energy densities, there is a window of luser energy density, typicully $1.5-3 \mathrm{~J} / \mathrm{cm}^{2}$ for excimer lasers, for thin film deposition.

Furthermore, at fixed energy densities, the composition of the deposited films of $\mathrm{ReBa}_{2} \mathrm{Cu}_{3} \mathrm{O}_{7-x}(\mathrm{Re}=\mathrm{Y}, \mathrm{Dy}, \mathrm{Ho}, \mathrm{Er}, \mathrm{Gd}, . .$.$) was not effected by the deposition chamber$ background pressure and the substrate temperature up to $800 \mathrm{C}[14]$. This unique feature of laser deposition makes thin film fabrication much easier. 


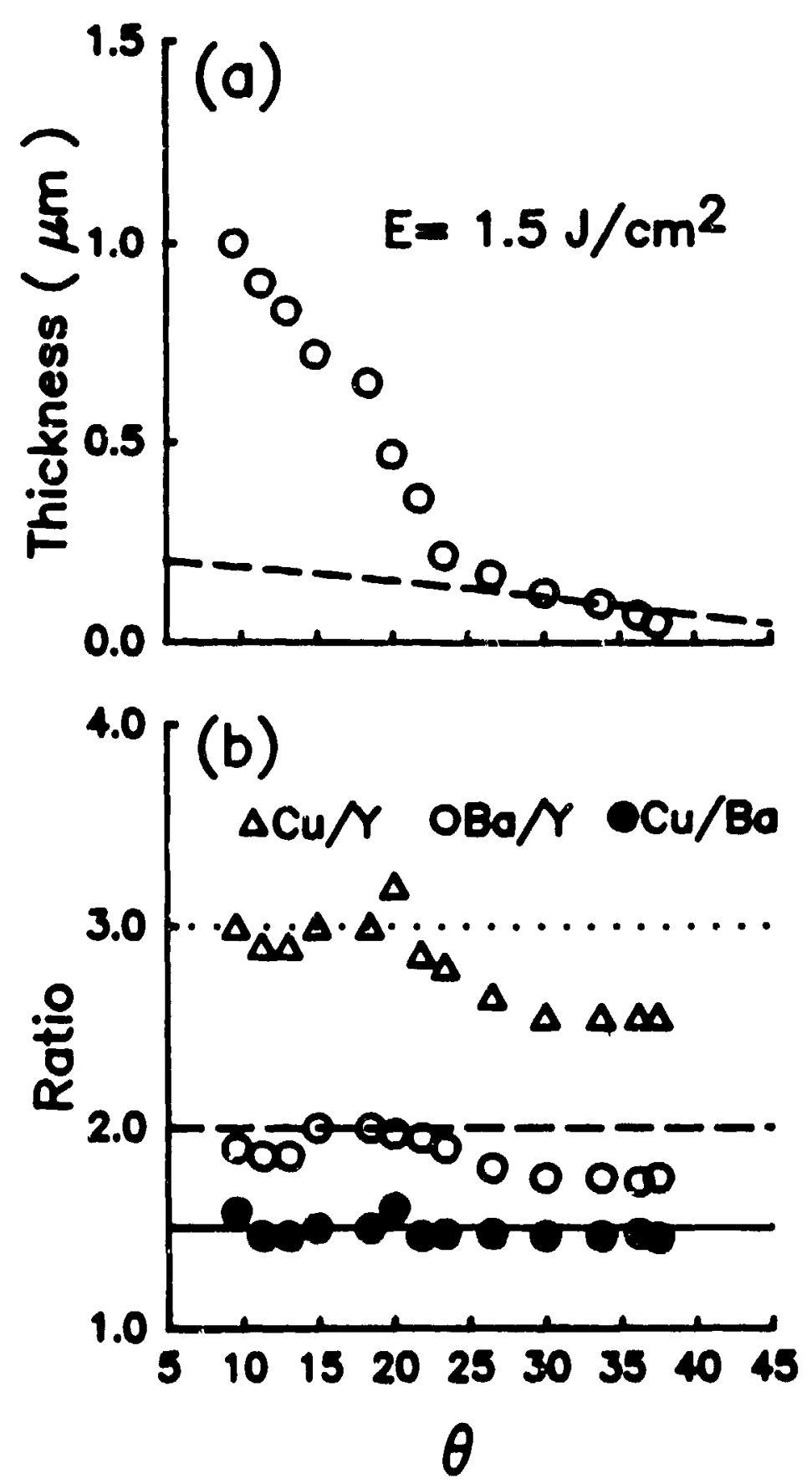

Fig. 2. At $1.5 \mathrm{~J} / \mathrm{cm} 2$ laser $(248 \mathrm{~nm}, 30 \mathrm{~ns})$ energy density, the angular distribution of the deposited film: (a) thickness (the dashed line is the $\cos \theta$ fit) and (b) composition. 


\section{SUPERCONDUCTIRG THIN FILMS}

Once the correct composition in the films are obtained, there are still two obstacles to be overcome before one can have good superconducting films. The atoms in the film must in the right crystallographic phase and the right amount of oxygen needs to be incorporated into the structure.

There are at least two approaches [3] to accomplishing this: one is to depusit the film in some random phases at a relatively low temperature and follow this up with a high temperature $(800-900 \mathrm{C})$ anneal in oxygen. But the high temperature treatment creates a number of problems [15]: the interface,

1. chemical reaction with the substrate resulting in the formation of a dead layer at

2. loss of film stoichiometry after annealing due to film-substrate interaction, and

3. crack formation during thermal cycling destroying the percolation path for superconductivity in the film.

These lead to poor reproducibility and performance of the films.

A more elegant way to accomplish the goal is to deposit the films directly in the crystalline phase at a temperature of $600-700 \mathrm{C}$ in an oxygen ambient. From a technological point of view, in order to produce sharp intertaces and minimize filmsubstrate interaction and stresses in the films, a low temperature process is absolutely essential. With the second approach epitaxial films with superior superconducting properties could be prepared since the films are grown layer-by-layer.

The first experiment on the low temperature process was done at a deoosition temperature of $650 \mathrm{C}$ and $5 \mathrm{mT}$ Torr of oxygen [16]. As shown in Fig. 3, the as-deposited film was oxygen deficient, and low temperature annealing pushed the superconducting transition temperature over $80 \mathrm{~K}$. The films made by this process were very smooth and shiny, and had a sharp interface with the substrate.

By simply increasing the oxygen pressure during deposition from $5 \mathrm{mTorr}$ to $100-200$ mTori and using substrate temperature between $650-750 \mathrm{C}$, high quality superconducting thin films were obtained without further heat treatment after couling down to room temperature in over 200 Torr of oxygen [17-21]. Higher oxygen pressure in the system enhances the formation of sub-oxides in the gas phase [22], and higher substrate temperature helps the film nucleation. A typical resistivity vs temperature is shown in Fig. 4 for a film deposited under those conditions. The film is highly metallic with a transition temperature and width of over $90 \mathrm{~K}$ and less than $1 \mathrm{~K}$, respectively.

A $10 \mathrm{~nm}$ thick $\mathrm{YBa}_{2} \mathrm{Cu}_{3} \mathrm{O}_{7}$ film on $\mathrm{SrTiO}_{3}$ made by pulsed laser deposition had a transition temperature of $82 \mathrm{~K}$ [2] , which is as good as thosc made by other techniques [23-24]. YBaCuO thin films made by laser deposition in-situ have one of the highest critical current densities $\left(-5 \times 10^{6} \mathrm{~A} / \mathrm{cm}^{2}\right)$ at $77 \mathrm{~K}$. Those films are also highly oriented with c-axis normal to the film surfaces, and crystalline with RBS clianneling minimum yields of $-3 \%$ [25], which are as good as those sbtained on bulk single crystals [26]. The films also exhibited the lowest flux noise measured to date [27], which further confirmed the high quality of the films. In-situ $\mathrm{YBaCuO}$ films on $\mathrm{LaAlO}_{3}$ had a order of magnitude lower surface resistances compared to $\mathrm{Cu}$ at $77 \mathrm{~K}$ at a few GHz [25], showing promising future for microwave apolications.

More recently, high quality $\mathrm{YBaCuO}$ superconducting thin films have been prepared in-siru by pulsed laser deposition at a deposition rate up to $14.5 \mathrm{~nm} / \mathrm{s}$ [28], which is two orders of magnitude higher than the conventional rate of typically $\sim 0.1 \mathrm{~nm} / \mathrm{s}$. Those films had superconducting transition temperatures of $90 \mathrm{~K}$. What is more remarkable is that the films at $77 \mathrm{~K}$ exhibited no marked degradation of current carrying capacity with 


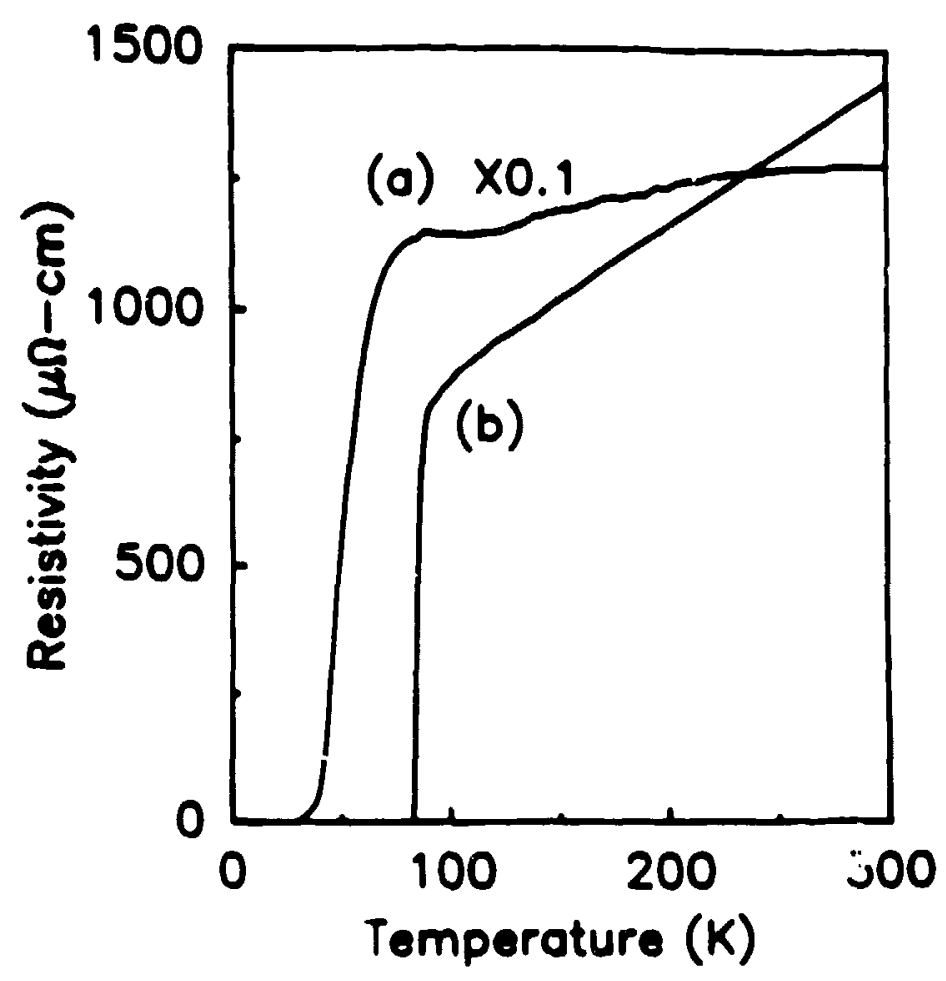

Fig. 3 Resistivity vs temperature for (a) an as-deposited YBaCuO film on (110) $\mathrm{SrTiO}_{3}$ made at $650 \mathrm{C}$ in $5 \mathrm{mtorr}$ oxygen, and (b) the same film after annealing in oxygen at $450 \mathrm{C}$ for $3.5 \mathrm{~h}$.

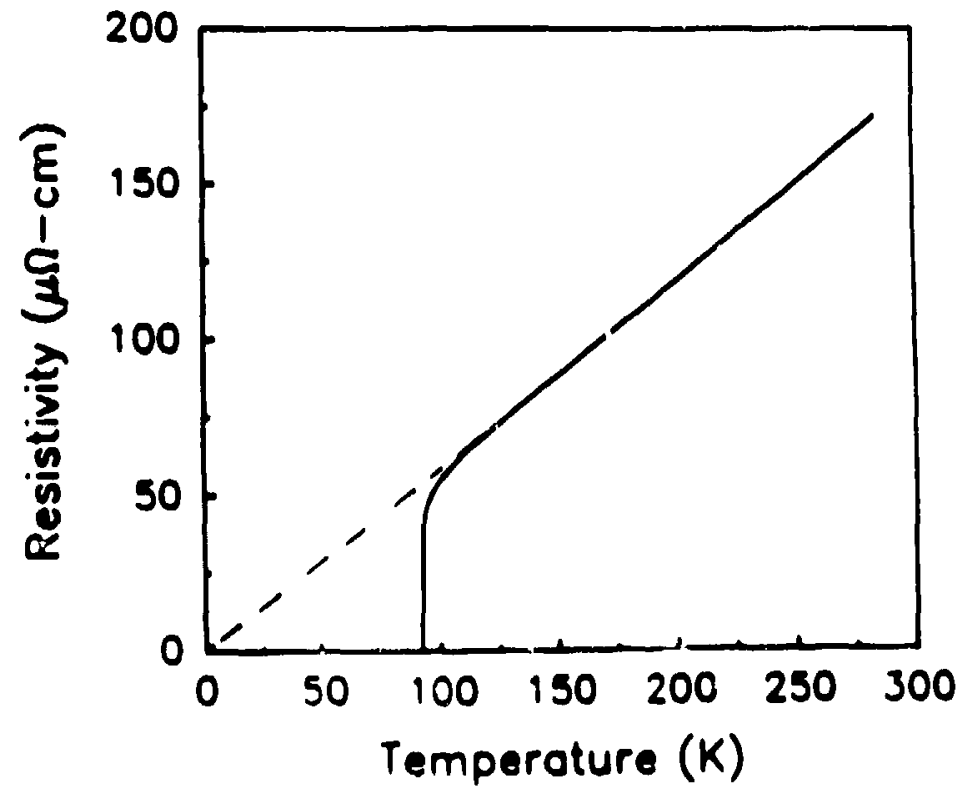

Fig. 4 Resistivity vs temperature for an as-deposited $100 \mathrm{~nm} \mathrm{YBaCuO}$ film on $\mathrm{SrTiO}_{3}$ made at $30 \mathrm{C}$ in $200 \mathrm{mTorr}$ oxygen. 
critical current densities of $4 \times 10^{6} \mathrm{~A} / \mathrm{cm}^{2}$ [29]. The high deposition rate achieved by the laser deposition enhances the efficiency of the technique.

\section{HETEROSTRUCTURES AND SUPERLATTICES}

In order to fabricate planar junction devices such as superconductor-normal metalsuperconductor (SNS) or superconductor-insulator-superconductor (SIS), heterostructure systems are needed. Since the high $T_{c}$ superconductors are crystalline materials, lattice matched multilayers are the only choice in order to have the superconductor maintain its transition temperature or order parameter right up to the interfaces. From the material growth point of view, the processing conditions should be very similar for all matched materials to assure the quality.

One of matched materials for $\mathrm{YBaCuO}$ is $\mathrm{Y}_{1-\mathrm{Y}} \mathrm{Pr}_{\mathrm{y}} \mathrm{Ba}_{2} \mathrm{Cu}_{3} \mathrm{O}_{7 \cdot x}(y=0$ to 1$)$, which has an orthorhombic structure with nearly the sam a lattice constants over the entire alloying range [30]. YPrBaCuO thin films can be prepared at same processing conditions as YBaCuO films [31]. Most of the substrate materials can be also used as the matched systems.

Multi-layers were accomplished by laser deposition in-situ by employing a multitarget holder, which allows different targets to be placed in the laser beam. By alternating the targets, heterostructures were fabricated. Epitixal growth of $\mathrm{YBaCuO} / \mathrm{PrBaCuO} / \mathrm{YBaCuO}$ trilayers [32] has been shown with the demonstration of ac and dc Jesophson effects in the SNS junction devices fabricated from such trilayer structures [33]. $2.8 \mathrm{MeV}$ He ion backscattering minimum yield of $6 \%$ on the YBaCuO top layer was observed, indicating high crystalline nature of the trilayers [32].

As increasing the number of the layers and reducing the individual layer thickness of the heterostructure, a superlattice including two or more different materials is formed. By fabrication of the superlattices, one will be enable to form possible new metastable phases, and study the charge transfer effects due to alloying in the various sites, proximity effects at the interfaces, and so on. Moreover, fabrication of the superconductor superlattices in a controlled way may lead to layer by layer synthesis of high quality superconducting thin films.

Fabrication of multilayered $\mathrm{Bi}(\mathrm{Pb})-\mathrm{Sr}-\mathrm{Ca}-\mathrm{Cu}-\mathrm{O}$ thin films by laser deposition of suscessive layers was reported by Kanai et. al. [34] More recently, excellent $\mathrm{YBaCuO} / \mathrm{DyBaCuO}$ superlattices with the shortest periodicity of $2.4 \mathrm{~nm}$ have been made by DC magnetron sputtering [35]. Epitaxial YB CuO/PrBaCuO superlattices with a simila! periodicity were prepared by a pulsed laser deposition technique [36]. The composition oscillations in the superlattices (Fig. 5) and the presence of the satellite peaks in $x$-ray diffraction spectrum demonstrated the periodicity was achieved in the structures. High quality of the superlattices was confirmed by showing a $1.2 \mathrm{~nm}$ YBaCuO layer separated by $10 \mathrm{~nm}$ PrBaCuO layer, which is insulating at low temperatures, was still superconducting abov: $4 \mathrm{~K}$ [37]. The transport measurements on the superlattices revealed interesting physics [37].

\section{DEPOSITION TEMPERATURES}

At present, the deposition temperature needed for high quality superconducting thin films is still high $(650-730 \mathrm{C})$ for all the thin film deposition techniques. Reducing the processing temperature is one of dreams for all the researchers. One of the ideas is to create more reactive oxygen by using an oxygen plasmas [38], and ozone [39]. Witanachchi et. al. [40] used a $+300 \mathrm{~V}$ bias potential between the target and substrate during laser deposition to enhance the laser generated plasma plum. It was found that the substrate temperature could be reduced by 50 to $100 \mathrm{C}$ to obtain same superconducting transition temperatures. Further experiment by Koren et. al. [41] using the atomic oxygen produced by photodissociation of $\mathrm{N}_{2} \mathrm{O}$ also indicated the importance of the atomic oxygen. It should 
be noted that the effect of atomic oxygen could be only seen at temperatures below $600 \mathrm{C}$ [40-42], and the superconducting transition temperatures and critical current densities of thin films made under those conditions are not as good as those made at higher substrate temperature. Further research is still needed to reduce the processing temperature and at same time maintain the quality of the films.

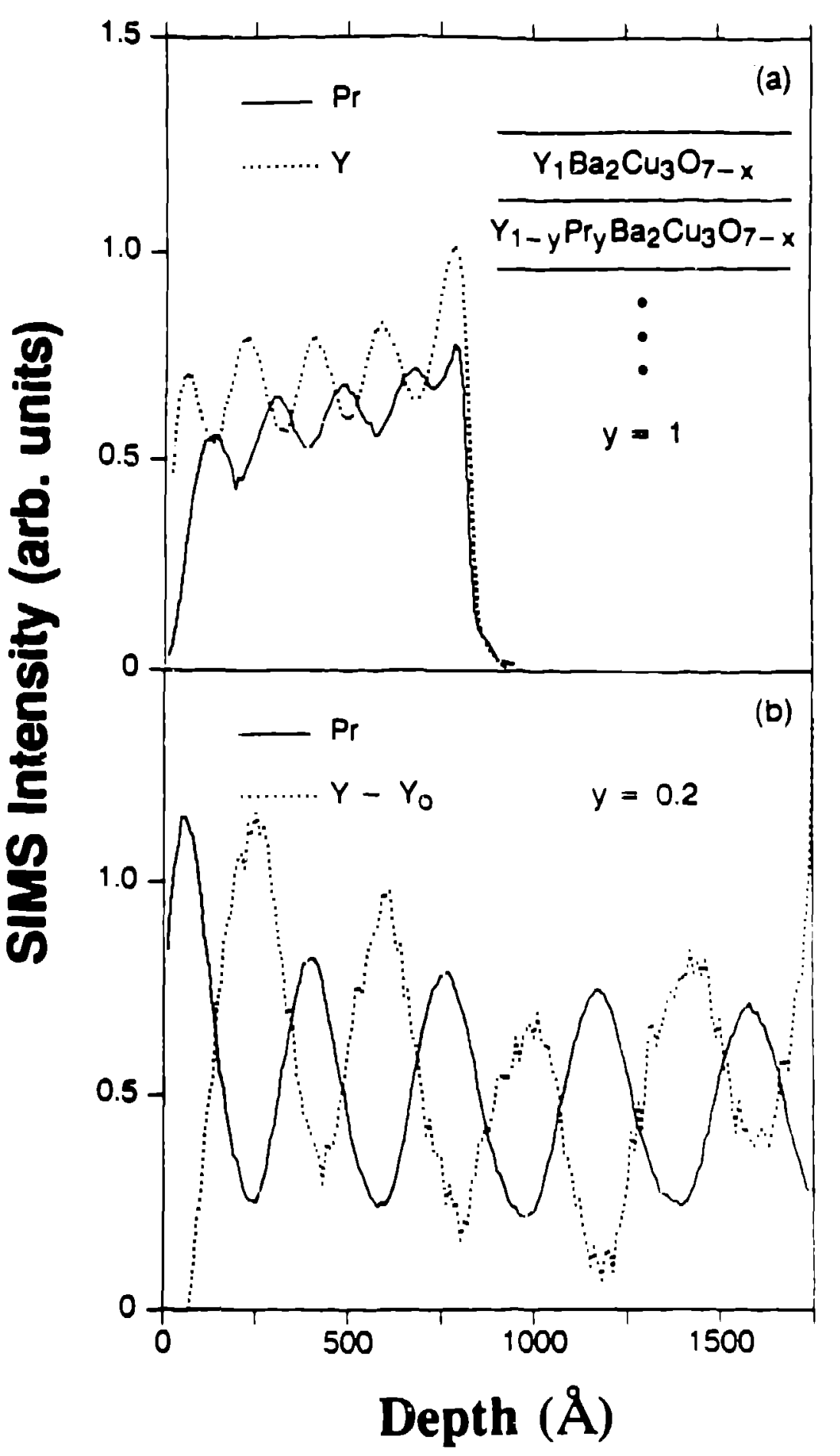

Fig. 5 SIMS data for two superlattices with different layer thickness:

(a) $9 \mathrm{~nm} \mathrm{YBaCuO} / 9 \mathrm{~nm} \mathrm{PrBaCuO}$, and (b) $20 \mathrm{~nm} \mathrm{YBaCuO} / 20 \mathrm{~nm}$ Y0.8Pr0.2BaCuO. Yo is $-75 \%$ of the maximum $Y$ signal. $Y$ and $\operatorname{Pr}$ signals are exactly out of phase. 


\section{ADVANTAGES AND DISADVANTAGES}

As mentioned above, the most important feature of pulsed laser deposition is the stoichiometric deposition. The use of a single target simplifies the deposition process [3]. Only single target sputtering such as inverted cylindrical magnetron sputtering [43] and offaxis sputtering [44] can compete with the pulsed laser deposition in these two areas. The versatility is an extra feature for the laser deposition. Simply shifting the targets, different materials or multi-layers are formed. The recent demonsiration of high deposition rate using pulsed laser deposition is a plus. Another advantage of the technique is that a small amount of materials is enough as source materials and the target usage is much higher compared to sputtering.

To further demonstrate the advantages, a thin film was made from a small piece of Berlin Wall by pulsed laser deposition at room temperature in vacuum. Fig. 6 shows a RBS spectrum of the film on a carbon substrate, clearly indicating the existence of $\mathrm{Ca}, \mathrm{Si}, \mathrm{Fe}$ and $O$ in the film. The composition of the film is close to the target average composition.

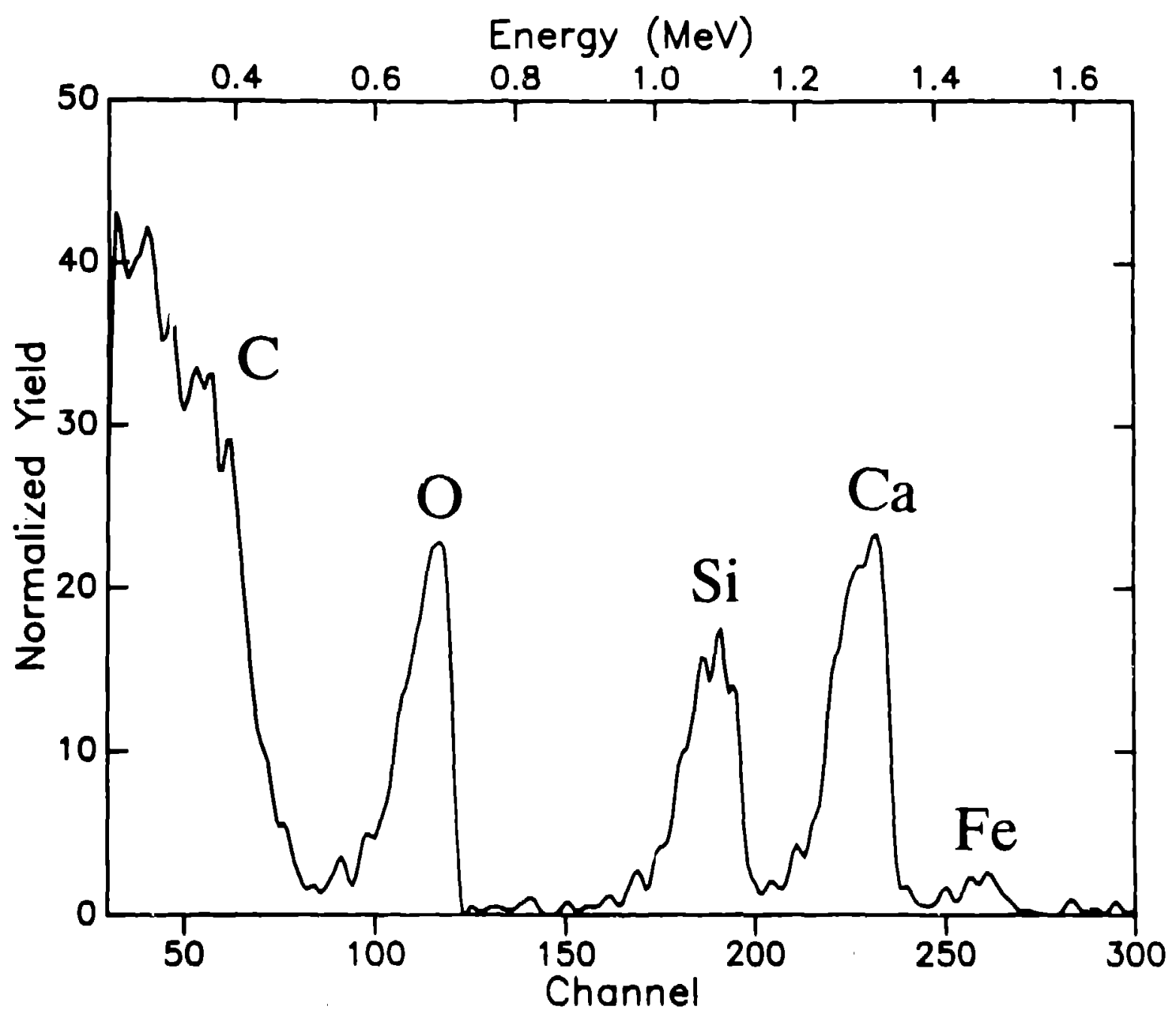

Fig. 6 A RBS (2 Mev He ions) spectrum of an as-depositd film on a carbon substrate made in vacuum from a small piece of Berlin Wall. The result indicates that laser deposition is a versatile thin film technique. 
The main disadvantage of the technique is that the laser-solid interaction process is not fully understood at this time [3]. Much more work should be done in this area. Another problem is that there are always particles on the smooth surface of the films deposited by the laser technique. By using short wavelength lasers, the density and average size of the particles are relatively reduced [5]. For a single layer thin films, so far no measurements have shown that the existence of particles is degrading the superconducting properties of the films. Certainly, the particles should be removed in order to prevent possible shorting in the multilayers. The high cost of lasers is another concern.

One of the popular questions is whether the techniques can be scaled up. Since the deposition is highly forward-directed, one can image the laser deposition as a spray gun. By relative movement of the gun or the substrate holder, large area coating will be possible. It is believed that it is an engineering problem.

\section{CONCLUSION}

The successful use of pulsed laser deposition of high $T_{c}$ superconducting thin films will bring more research in the technique. Detailed research is needed for further development of the technique. It is obvious that pulsed laser deposition will be one of the most important thin film techniques not only for research but also for manufacturing.

\section{ACKNOWLEDGMENTS}

The authors would like to thank many individuals at Bellcore, Rutgers, Los Alamos and many other institutions for helpful discussions and experimental collaborations over the last three years during the time pulsed laser deposition technique was developed for high temperature superconductors. The work at Los Alamos was partial supported by the DOE Los Alamos Superconductivity Pilot Center.

\section{REFERENCES}

[1] J. T. Cheung and H. Sankur, CRC Crit. Rev. Solid State Mater. Sci. 15, 63(1988)

(2) I. W. Boyd, Laser Processing of Thin Films and Microstructures: Oxidation. Deposition and Etching of Insulators, (Springer-Verlag, New York, 1987).

[3] X. D. Wu, PhD Thesis, Rutgers University, 1989.

[4] H. P. Geserich, B. Koch, G. Scheiber, J. Geerk, H. C. Li, G. Linker, W. Weber, and W. Assmus, Physica C 153-155, 661(1988).

[5] G. Koren, A. Gupta, R. J. Baseman, M. I. Lutwyche, and R. B. Laibowitz, Appl. Phys. Lett. 55, 2450(1989).

[6] L Lyon, B. R. Weinberger, G. G. Peterson, and H. A. krasinski, Appl. Phys. Lett. 52, 320(1988).

[7] M.K. Wu, J. R. Ashburn, C. T. Torng, P. H. Hor, R. L. Meng, L. Gao, Z. L. Huistg, Y. Q. Wang, and C. W. Chu, Phys. Rev. Lett. 58, 908(1987).

[8] H. Maeda, Y. Tanaka, M. Fukutumi and T. Asano, Jpn. J. Appl. Phys. 27, L209(1988); J. M. Tarascon, Y. LePage, L. H. Greene, B. G. Bagley, P. Barboux, D. M. Hwang, G. W. Hull, W. R. McKinnon and M. Giroud, Phys. Rev. B38, 2504(1988).

[9] Z. Z. Sheng and A. M. Herman, Nature 332, 55(1988); 332, 138(1988); S. S. Parkin, V. Y. Lee, E. M. Engler, A. I. Nazzal, T. C. Huang, G. Gorman, R. Savoy and R. Beyers, Phys. Rev. Lett. 60, 2539(1988).

[10] S. V. Zaitsev-Zotov, A. N. Martynyuk, and E. A. Protasov, Sov. Phys. Soild State 25, 100(1983).

[11] D. Dijkkamp, T. Venkatesan, X. D. Wu, S. A. Shaheen, N. Jisrawi, Y. H. Min-Lee, W. L. McLean, and M. Croft, Appl. Phys. Lett. 51, 619(1987).

[12] T. Venkatesan, X. D. Wu, A. Inam, Y. Jeon, M. Croft, E. W. Chase, C. C. 
Chang, J. B. Wachtman, R. W. Odom, F. Radicati, and C. A. Magee, Appl. Phys. Lett. 33, 1431(1988).

[13] T. Venkatesan, X. D. Wu, A. Inam and J. B. Wachtman, Appl. Phys. Lett 52 , 1193(1988).

[14] X. D. Wu, T. Venkatesan, A. Inam, E. W. Chase, C. C. Chang, Y. Jeon, M. Croft, C. Magee, R. W. Odom, and F. Radicati, in Proc SPIE - High $T_{s}$ Superconductivity: Thin Films and Deviees, 948, 50(1988).

[15] T. Venkatesan, C. C. Chang, D. Dijkkamp, E. W. Chase, D. M. Hwang, S. A. Schwar, P. F. Miceli, L. A. Garrow. I. M. Tarascon, X. D. Wu, and A. Inam, J. Appl. Phys. 63, 4591(1988).

[16] X. D. Wu, A. Inam, T. Venkatesan, E. W. Chase, P. Barboux, J. M. Tarascon and B. Wilkens, Appl. Phys. lett. 52, 754(1988).

[17] G. Koren, E. Polturak, B. Fisher, D. Cohen and G. Kimel, Appl. Phys. Lett. 63, 2330(1988); G. Koren, A. Gupta, E. A. Giess, A. Segmuller and R. B. Laibowitz, Appl. Phys. Lett. 54, 1054(1989).

[18] B. Roas, L Schultz and G. Endres, Appl. Phys. Lett. 53, 1557(1988).

[19] A. I. Golovashikin, E. V. Ekimov, S. I. Krasncsvobodtsev and E. V. Pechen, Physica C 153-155, 1455(1988).

[20] J. Frohlingsdrof, W. Zander and B. Stritzker, Soild State Comm. 67, 965(1988).

[21] T. Venkatesan, X. D. Wu, B. Dutta, A. Inam, M. S. Hegde, D. M. Hwang, L Nazar and B. Wilkens, Appl. P.hys. lctt. 54, 581(1989).

[22] X. D. Wu, B. Dutta, M. S. Hedge, A. Inam, T. Venkatesan, E. W. Chase, C. C. Chang, and R. Howard, Appl. Phys. Lett. 54, 179(1989).

[23] Y. Bando, $T$. Terashima, K. ijima, K Yamamoto, K. Hirata and H. Mazaki, in Proceedings of the Symposium of the Materials Research Society (Tokyo, 1988).

[24] X. X. Xi, J. Geerk, G. Linker, Q. Li, and O. Meyer, Appl. Phys. Lett. 54, 2367(1989).

[25] A. Inam, X. D. Wu, I. Nazar, M. S. Hegde, C. T. Rogers, T. Venkatesan, R. Simon, K. Daly, H. Padamsee, J. Kirchgessner, D. Moffat, D. Rubin, Q. Shi, D. Kalokitis, A. Fathy, V. Pendrick, R. Brown, B. Brycki, E. Belohoubek, L. Drabeck, G. Gruner, R. Hammond, F. Gamble, B. Lairson and J. B. Bravman, Appl. Phys. Lett. 56, 1178(1989)

[26] M. J. Ferrari, M. Johnson, F. C. Wellstood, J. Clarke, A. Inam, X. D. Wu, L. Nazar and T. Venkatesan, Nature, 341, 723(1989).

[27] N. D. Stoffel, P. A. Morris, W. A. Bonner, and B. J. Wilkens, Ptys. Rev. B37, 2297(1988).

[28] X. D. Wu, R. E. Muenchausen, S. Foltyn, R. C. Estler, R. C. Dye, C. Flamme, N. S. Nogar, A. R. Garcia, J. Martin and J. Tesiner, Appl. Phys. Lett. 56, 1481 (i990)

[29] X. D. Wu, R. E. Muenchausen, S. Foltyn, R. C. Estler, R. C. Bye, A. R. Garcia, N. S. Nogar, P. England, R. Ramesh, D. M. Hwang, T. S. Ravi, C. C. Chang, T. Venkatesan, X. X. Xi, Q. Li and A. Inam, Appl. Phys. Lett. (submitted).

[30] L. Soderholm, K. Zhang, D. H. Hinks, M. A. Beno, J. D. Jorgensen, C. U.

Segre, and I. K Schuller, Nature. 328, 604(1987); B. Okai, M. Kosuge, H. Nozaki, K. Takahashi, and M. Ohta, Jpn. J. Appl. Phys. 27, 41(1988); M. Matsuda, K. Kinoshita, T. Ishii. H. Shibada, T. Watanabe and T. Yamada, Phys. Rev. B38, 2910(1988).

[31] X. D. Wu, M. S. Hegde, X. X. Xi, Q. Li, A. Inam, S. A. Schwarz, J. A. Martinez, B. J. Barner, C. C. Chang, L. Nazar, C. T. Rogers and T. Venkatesan, in Proc of Materials Research Sociecry (Boston, 1989) (in press).

[32] T. Venkatesan, A. Inam, B. Dutta, R. Ramesh, M. S. Hegde, X. D. Wu, L. Nazar, C. C. Chang, J. B. Barner, D. M. Hwang, and C. T. Rogers, Appl. Phys. Lelt. 56, 391(1989).

[33] C. T. Rogers, A. Inam, M. S. Hegde, B. Dutta, X. D. Wu, and T. Venkatesan, Appl. Phys. Lett. 55, 2032(1989).

[34] M. Kanai, T. Kawai, S. Kawai and H. Tabata, Appl. Phys. Lett. 54, 1802(1989).

35] J.-M. Triscone, M. G. Karkut, L. Antognazza, O. Brunner and O. Fischer, Phys. Rev. Lett, 55, 2032(1989).

[36] X. D. Wu, X. X. Xi, Q. Li, A. Inam, B. Dutta, L. DiDomenico, C. Weiss, J. A. Martinez, B. J. Wilkens, S. A. Schwar, J. B. Barner, C. C. Chang, L Nazar, and T. Venkatesan, Appl. Phys. Lett. S6, 400(1989).

[37] Q. Li, X.X.Xi, X. D. Wu, A. Inam, S. Vadlamannati, W. L. McLean, T. 
Venkatesan, R. Ramesh, J. A. Martinez and L. Nazar, Phys. Rev. Lett. (submitted).

[38] T. Terashima, K. Ijima, K. Yamamoto, Y. Bando and H. Mazaki, Jpn.

J. Appl. Phys. 27, L91(1988).

[39] D. D. Berkley, B. R. Johnson, N. Anand, K. M. Beauchamp, L. E. Conroy, A. M. Goldman, K. Mauersberger, M. L. Mecartney, J. Norton, M. Tuominen and Y-J. Zhang, Appl. Phys. Lett. 53, 1973(1988).

[40] S. Witanachchi, H. S. Kwok, X. W. Wang, and D. T. Shaw, Appl. Phys. Lett. 53, 234(1988).

[41] G. Koren, A. Gupta, and R. J. Baseman, Appl. Phys. Lett. 54, 1920(1989).

42] R. K. Singh, J. Narayan, A. K. Singh, and J. Krishnaswarmy, Appl. Phys. Lett.

[43] X. X. Xi, H. C. Li, J. Geerk, G. Linker, O. Meyer, B. Obst, F. Ratzel, R.

Smithey, and F. Weschenfelder, Physica C 153-155, 794(1988).

[44] R. L. Sandstrom, W. J. Gallagher, T. R. Dinger, R. H. Koch, R. B. Laibowitz, A. W. Kleinsasser, R. J. Gambino, B. Bumble and M. F. Chisholm, Appl. Phys. Lett. 53, 444(1988); C. B. Eom, J. Z. Sun, K. Yamamoto, A. F. Marshall, K. E. Luther, T. H. Geballe, S. S. Laderman, Appl. Phys. Lett. 55, 595(1989). 